\title{
Uric acid is an independent risk factor for carotid atherosclerosis in a Japanese elderly population without metabolic syndrome
}

\author{
Shuzo Takayama ${ }^{1,2}$, Ryuichi Kawamoto ${ }^{1,3^{*}}$, Tomo Kusunoki ${ }^{1,3}$, Masanori Abe ${ }^{1,2}$ and Morikazu Onji
}

\begin{abstract}
Background: Carotid intima-media thickness (IMT) is an useful surrogate marker of cardiovascular disease. Associations between uric acid (UA), metabolic syndrome (MetS) and carotid IMT have been reported, but findings regarding the relationship have been inconsistent.

Methods: A total of 1,579 Japanese elderly subjects aged $\geq 65$ years $\{663$ men aged, $78 \pm 8$ (mean \pm standard deviation) years and 916 women aged $79 \pm 8$ years\} were divided into 4 groups according to UA quartiles. We first investigated the association between UA concentrations and confounding factors including MetS; then, we assessed whether there is an independent association of UA with carotid IMT and atherosclerosis in participants subdivided according to gender and MetS status.

Results: Carotid IMT was significantly increased according to the quartiles of UA in both genders without MetS and women with MetS. Multivariate logistic regression analysis showed that odds ratio (OR) $\{95 \%$ confidence interval (CI)\} in men for carotid atherosclerosis was significantly increased in the third $(\mathrm{OR}, 1.75 ; 95 \% \mathrm{Cl}, 1.02-3.02)$, and fourth quartiles $(\mathrm{OR}, 2.01 ; 95 \% \mathrm{Cl}, 1.12-3.60)$ of $\cup A$ compared with that in the first quartile of $\cup A$, and the $O R$ in women was significantly increased in the fourth quartile $(\mathrm{OR}, 2.10 ; 95 \% \mathrm{Cl}, 1.30-3.39)$. Similarly, the ORs were significantly associated with increasing quartiles of UA in both genders without MetS, but not necessarily increased in those with MetS.
\end{abstract}

Conclusions: UA was found to be an independent risk factor for incidence of carotid atherosclerosis in both genders without MetS.

Keywords: uric acid, metabolic syndrome, carotid atherosclerosis, cardiovascular risk factor, gender

\section{Introduction}

Metabolic syndrome (MetS) is a cluster of metabolic abnormalities defined as the clustering of several cardiovascular risk factors in an individual that include visceral obesity, insulin resistance, raised blood pressure (BP), hypertriglyceridemia, low high-density lipoprotein (HDL) cholesterolemia, and impaired fasting plasma glucose (FPG) [1,2], and that it is a predictor of cardiovascular disease (CVD) [3-5]. Population-based studies have shown that MetS is quite common, affecting 13.3 24.4\% of Japanese men $\geq 30$ years of age [6], and its prevalence

\footnotetext{
* Correspondence: rykawamo@yahoo.co.jp

'Department of Community Medicine, Ehime University Graduate School of Medicine; Ehime 791-0295, Japan

Full list of author information is available at the end of the article
}

is increasing with the continuous increase in obesity prevalence in Japan.

Uric Acid (UA) is the metabolic end product of purine metabolism in humans; excess accumulation can lead to various diseases [7]. Many previous studies have shown that increased UA levels are also associated with components of MetS and often accompanied by obesity, raised BP [8], hyperlipidemia [9], glucose intolerance [10], and CVD clustering [11], all of which play a causal role in the pathogenesis of CVD. Thus, UA seems to be merely an independent risk factor or marker for atherosclerosis $[12,13]$. However, its importance as a risk factor is still controversial. Sakata et al. showed that UA levels are not related to increased risk of death from all causes, including CVD and stroke in 8,172 Japanese participants

\section{Ciomed Central}


aged $\geq 30$ years [14]. We have demonstrated that UA is more strongly associated with MetS in women than in men, and associated with the prevalence of carotid atherosclerosis (intima-media thickness (IMT) $\geq 1.0 \mathrm{~mm}$ \} only in men without MetS but not in men with MetS or in women with or without MetS [15]. Associations between UA, MetS and carotid IMT have been reported, but few of the studies have been conducted in Japanese subjects.

In the present study, we first investigated the association between UA levels and confounding factors including MetS; currently defined as at least 3 of the 5 following conditions: visceral obesity, raised BP, hypertriglyceridemia, low HDL cholesterolemia, and impaired FPG. In addition, we also assessed whether there is an independent association of UA with carotid atherosclerosis in individuals subdivided according to gender and MetS status.

\section{Materials and methods Subjects}

Subjects for this investigation were recruited from among consecutive elderly patients aged $\geq 65$ years visited the medical department of Seiyo Municipal Nomura Hospital. Participants with severe cardio-renal or nutritional disorders that would affect BP, lipid and glucose metabolism were excluded. Thus, 1,579 patients were enrolled in the study. All procedures were approved by the Ethics Committee of Seiyo Municipal Nomura Hospital, and written informed consent was obtained from each subject.

\section{Evaluation of Risk Factors}

Information on demographic characteristics and risk factors were collected using the clinical files in all cases. Body mass index (BMI) was calculated by dividing weight (in kilograms) by the square of the height (in meters). We measured BP in the right upper arm of patients in a sedentary posture using a standard sphygmomanometer or an automatic oscillometric BP recorder. Smoking status was defined as the number of cigarette packs per day multiplied by the number of years smoked (pack.year) irrespective of the differentiation of current and past smoking status: never, light (< 20 pack.year), heavy ( $\geq 20$ pack.year). Alcohol consumption was classified into non-drinker and drinker (available data, $\mathrm{n}=1,145)$. Histories of antihypertensive, antilipidemic, and antidiabetic medication use were also evaluated. Moreover, ischemic stroke and ischemic heart disease were defined as CVD. Total cholesterol (T-C), triglyceride (TG), HDL cholesterol (HDL-C), FPG, and UA were measured under a fasting condition. Low-density lipoprotein cholesterol (LDL-C) level was calculated by the Friedewald formula [16], and patients with TG levels $\geq 400 \mathrm{mg} / \mathrm{dl}$ were excluded. The mean UA was significantly lower in women $[5.1 \pm 2.0$ \{mean \pm standard deviation $(\mathrm{SD})\} \mathrm{mg} / \mathrm{dl}]$ than in men $(5.7 \pm 2.0 \mathrm{mg} /$ $\mathrm{dl} ; \mathrm{p}<0.001)$. Therefore, sex-specific quartiles of UA were used. The mean (range) UA values of 3.5 (0.8 to 4.3), 5.0 (4.4 to 5.5), 6.1 (5.6 to 6.8), and 8.4 (6.9 to 16.1) $\mathrm{mg} / \mathrm{dl}$ were used for men, and 3.1 (0.5 to 3.8$), 4.3$ (3.9 to 4.7 ), 5.3 (4.8 to 6.0 ), and 7.7 (6.1 to 15.4 ) were used for women (Table 1).

\section{Ultrasound image analysis}

An ultrasonograph (Hitachi EUB-565, Aloka SSD-2000, or Prosound- $\alpha 6$ ) equipped with a $7.5 \mathrm{MHz}$ linear type B-mode probe was used by a specialist in ultrasonography to evaluate sclerotic lesions of the common carotid arteries on a day close to the day of blood biochemistry analysis (within 2 days). Patients were asked to assume a supine position, and the bilateral carotid arteries were observed obliquely from the anterior and posterior directions. We measured the thickness of the intimamedia complex (IMT) on the far wall of the bilateral common carotid artery about $10 \mathrm{~mm}$ proximal to the bifurcation of the carotid artery (as the image at that site is more clearly depicted than that at the near wall) $[17,18]$ as well as the wall thickness near the $10 \mathrm{~mm}$ point on a B-mode monitor. We then used the mean value for analysis. Carotid plaques were considered as localized thickening and the echo luminance included those equal to high echogenic structures encroaching into the vessel lumen through common carotid artery to carotid bifurcation [17]. Carotid atherosclerosis was defined as IMT $\geq 1.0 \mathrm{~mm}$ or plaque lesion [17-19].

\section{MetS}

We applied condition-specific cutoff points for MetS based on the modified criteria of the National Cholesterol Education Program's Adult Treatment Panel (NCEP-ATP) III report [2]. MetS was defined as subjects with at least three or more of the following five conditions: 1) obesity: BMI $\geq 25.0 \mathrm{~kg} / \mathrm{m}^{2}$ according to the guidelines of the Japanese Society for the Study of Obesity (waist circumference was not available in this study) [20,21]; 2) raised BP with a systolic BP (SBP) $\geq 130 \mathrm{mmHg}$ and/or diastolic BP (DBP) $\geq 85 \mathrm{mmHg}$, and/or current treatment for hypertension; 3 ) hypertriglyceridemia with a TG level $\geq 150 \mathrm{mg} / \mathrm{dL}$; 4) low HDL cholesterolemia with a HDL-C level $<40 \mathrm{mg} / \mathrm{dL}$ in men and $<50 \mathrm{mg} / \mathrm{dL}$ in women and/or current treatment for dyslipidemia; and 5) impaired fasting glucose with a FPG level $\geq 100 \mathrm{mg} / \mathrm{dL}$ and/or current treatment for diabetes.

\section{Statistical analysis}

All values are expressed as the mean \pm standard deviation (SD), unless otherwise specified, and in the cases of 
Table 1 Characteristics of subjects

\begin{tabular}{|c|c|c|c|c|c|c|c|c|c|c|}
\hline \multirow[b]{2}{*}{$\begin{array}{l}\text { Uric acid range (mg/ } \\
\mathrm{dL})\end{array}$} & \multirow{2}{*}{$\begin{array}{c}\text { Men } \\
\text { UA-1 } \\
0.8-4.3 \\
\mathrm{~N}=169\end{array}$} & \multicolumn{3}{|c|}{ Quartile of serum uric acid } & \multirow[b]{2}{*}{$\begin{array}{l}P \text { for } \\
\text { trend* }\end{array}$} & \multirow{2}{*}{$\begin{array}{c}\text { Women } \\
\text { UA-1 } \\
0.5-3.8 \\
N=247\end{array}$} & \multicolumn{2}{|c|}{$\begin{array}{l}\text { Quartile of serum } \\
\text { uric acid }\end{array}$} & \multirow[b]{2}{*}{$\begin{array}{c}\text { UA-4 } \\
6.1-15.4 \\
N=221\end{array}$} & \multirow[b]{2}{*}{$\begin{array}{l}P \text { for } \\
\text { trend }\end{array}$} \\
\hline & & $\begin{array}{c}\text { UA-2 } \\
4.4-5.5 \\
N=171\end{array}$ & $\begin{array}{c}\text { UA-3 } \\
5.6-6.8 \\
N=163\end{array}$ & $\begin{array}{c}\text { UA-4 } \\
6.9-16.1 \\
N=160\end{array}$ & & & $\begin{array}{c}\text { UA-2 } \\
3.9-4.7 \\
N=213\end{array}$ & $\begin{array}{c}\text { UA-3 } \\
4.8-6.0 \\
N=235\end{array}$ & & \\
\hline Age (years) & $76 \pm 8$ & $78 \pm 7$ & $78 \pm 8$ & $79 \pm 7$ & 0.004 & $79 \pm 8$ & $78 \pm 8$ & $79 \pm 8$ & $82 \pm 8$ & $\begin{array}{c}< \\
0.001\end{array}$ \\
\hline Body mass indext $\left(\mathrm{kg} / \mathrm{m}^{2}\right)$ & $21.3 \pm 4.6$ & $21.9 \pm 3.2$ & $21.9 \pm 3.9$ & $21.8 \pm 4.0$ & 0.372 & $21.2 \pm 3.6$ & $22.1 \pm 3.4$ & $22.8 \pm 4.8$ & $22.3 \pm 4.8$ & $\begin{array}{c}< \\
0.001\end{array}$ \\
\hline $\begin{array}{l}\text { Smoking statusł(never/ } \\
\text { light/heavy, \%) }\end{array}$ & $\begin{array}{l}26.0 / 20.7 / \\
53.3\end{array}$ & $\begin{array}{l}32.2 / 19.9 / \\
48.0\end{array}$ & $\begin{array}{c}36.2 / 17.8 / \\
46.0\end{array}$ & $\begin{array}{l}35.6 / 16.9 / \\
47.5\end{array}$ & 0.517 & $\begin{array}{l}99.2 / 0.4 / \\
0.4\end{array}$ & $\begin{array}{l}96.2 / 0.5 / \\
3.3\end{array}$ & $\begin{array}{l}65.7 / 1.3 / \\
3.0\end{array}$ & $\begin{array}{l}93.7 / 2.7 / \\
3.6\end{array}$ & 0.043 \\
\hline $\begin{array}{l}\text { Alcohol consumption } 1, N \\
\text { (\%) }\end{array}$ & $78(67.8)$ & $70(60.9)$ & $65(59.1)$ & $65(66.3)$ & 0.470 & $1(0.6)$ & $3(1.8)$ & $6(3.3)$ & $5(2.8)$ & 0.286 \\
\hline $\begin{array}{l}\text { Systolic blood pressure } \\
(\mathrm{mmHg})\end{array}$ & $132 \pm 22$ & $141 \pm 22$ & $139 \pm 24$ & $136 \pm 25$ & 0.003 & $138 \pm 21$ & $139 \pm 20$ & $138 \pm 21$ & $136 \pm 28$ & 0.552 \\
\hline $\begin{array}{l}\text { Diastolic blood pressure } \\
(\mathrm{mmHg})\end{array}$ & $76 \pm 14$ & $78 \pm 13$ & $77 \pm 13$ & $76 \pm 14$ & 0.672 & $76 \pm 13$ & $76 \pm 11$ & $76 \pm 13$ & $72 \pm 16$ & 0.001 \\
\hline $\begin{array}{l}\text { Antihypertensive } \\
\text { medication, N (\%) }\end{array}$ & $65(38.5)$ & $75(43.9)$ & $88(54.0)$ & $82(51.3)$ & 0.019 & $116(47.0)$ & $105(49.3)$ & $140(59.6)$ & $146(66.1)$ & $\begin{array}{l}< \\
0.001\end{array}$ \\
\hline Total cholesterol (mg/dl) & $167 \pm 46$ & $168 \pm 42$ & $164 \pm 41$ & $171 \pm 45$ & 0.505 & $190 \pm 40$ & $188 \pm 42$ & $193 \pm 43$ & $181 \pm 44$ & 0.025 \\
\hline LDL-cholesterol (mg/dl) & $102 \pm 38$ & $104 \pm 33$ & $95 \pm 35$ & $105 \pm 38$ & 0.061 & $118 \pm 33$ & $114 \pm 35$ & $120 \pm 37$ & $110 \pm 35$ & 0.016 \\
\hline Triglyceride (mg/dl) & $68(52-93)$ & $73(56-98)$ & $76(57-112)$ & $89(69-127)$ & $\begin{array}{c}< \\
0.001\end{array}$ & $69(54-93)$ & $\begin{array}{l}80(59- \\
109)\end{array}$ & $\begin{array}{l}92(69- \\
124)\end{array}$ & $\begin{array}{l}94(67- \\
120)\end{array}$ & $\begin{array}{c}< \\
0.001\end{array}$ \\
\hline HDL-cholesterol (mg/dl) & $49 \pm 19$ & $47 \pm 15$ & $51 \pm 18$ & $45 \pm 15$ & 0.024 & $57 \pm 17$ & $56 \pm 18$ & $53 \pm 15$ & $51 \pm 17$ & $\begin{array}{c}< \\
0.001\end{array}$ \\
\hline $\begin{array}{l}\text { Antilipidemic drug use, N } \\
(\%)\end{array}$ & $9(5.3)$ & $7(4.1)$ & $8(4.9)$ & $8(5.0)$ & 0.959 & $17(6.9)$ & $13(6.1)$ & $17(7.2)$ & $26(11.8)$ & 0.115 \\
\hline $\begin{array}{l}\text { Fasting plasma glucose } \\
(\mathrm{mg} / \mathrm{dl})\end{array}$ & $\begin{array}{l}119(98- \\
152)\end{array}$ & $\begin{array}{l}112(95- \\
141)\end{array}$ & $\begin{array}{l}113(96- \\
150)\end{array}$ & $\begin{array}{c}115(96- \\
139)\end{array}$ & 0.404 & $\begin{array}{c}112(97- \\
146)\end{array}$ & $\begin{array}{c}108(94- \\
140)\end{array}$ & $\begin{array}{c}109(92- \\
130)\end{array}$ & $\begin{array}{l}118(97- \\
155)\end{array}$ & 0.061 \\
\hline $\begin{array}{l}\text { Antidiabetic medication, } \\
\text { N (\%) }\end{array}$ & $50(29.6)$ & $35(20.5)$ & $29(17.8)$ & $37(23.1)$ & 0.063 & $47(19.0)$ & $48(22.5)$ & $43(18.3)$ & $59(26.7)$ & 0.112 \\
\hline $\begin{array}{l}\text { Metabolic syndrome, N } \\
(\%)\end{array}$ & $32(18.9)$ & $50(29.2)$ & $44(27.0)$ & $54(33.8)$ & 0.022 & $62(25.1)$ & $71(33.3)$ & $87(37.0)$ & $97(43.9)$ & $\begin{array}{c}< \\
0.001\end{array}$ \\
\hline $\begin{array}{l}\text { Cardiovascular disease, N } \\
(\%)\end{array}$ & $65(38.5)$ & $85(49.7)$ & $82(50.3)$ & $83(51.9)$ & 0.055 & $87(35.2)$ & $84(39.4)$ & $97(41.3)$ & $91(41.2)$ & 0.448 \\
\hline $\begin{array}{l}\text { Ischemic stroke, } \\
\text { N (\%) }\end{array}$ & $59(34.9)$ & $74(43.3)$ & $73(44.8)$ & $75(46.9)$ & 0.131 & $77(31.2)$ & $73(34.3)$ & 78 (33.2) & $69(31.2)$ & 0.869 \\
\hline $\begin{array}{l}\text { Ischemic heart } \\
\text { disease, } \\
N(\%)\end{array}$ & $11(6.5)$ & $15(8.8)$ & $17(10.4)$ & $16(10.0)$ & 0.592 & $15(6.1)$ & $16(7.5)$ & $21(8.9)$ & $30(13.6)$ & 0.031 \\
\hline
\end{tabular}

$\mathrm{LDL}$, low-density lipoprotein; HDL, high-density lipoprotein. Plus-minus values are means \pm standard deviation. $\dagger$ Body mass index was calculated using weight in kilograms divided by the square of the height in meters. $¥$ Smoking status: daily consumption (pack) $\times$ duration of smoking (year): never, light $(<20$ pack year), and heavy ( $\geq 20$ pack.year). MAlcohol consumption was classified into non-drinker and drinker (available data, $n=1,145$ ). Data for triglycerides and fasting plasma glucose were skewed, and are presented as the median (interquartile range) and were log-transformed for analysis. ${ }^{*} P$-value: ANOVA or $\chi^{2}$-test.

parameters with non-normal distributions (TG, FPG), the data are shown as median (interquartile range) values. In all analyses, parameters with non-normal distributions were used after log-transformation. Statistical analysis was performed using PASW Statistics 17.0 (Statistical Package for Social Science Japan, Inc., Tokyo, Japan). The differences of means and prevalence among the groups were analyzed by ANOVA and $\chi^{2}$ test, respectively, and A post hoc analysis was performed with Dunnett's test. A multivariate logistic regression analysis was employed to evaluate the contribution of confounding risk factors (e.g., age, BMI, smoking status, SBP, DBP, antihypertensive medication, LDL-C, HDL-C, TG, antilipidemic medication, FPG, antidiabetic medication, and history of $\mathrm{CVD}$ ) for carotid atherosclerosis. A value of $\mathrm{p}<0.05$ was considered significant.

\section{Results}

\section{Background of Subjects}

Table 1 shows the clinical characteristics of the 663 male and 916 female subjects. Ages of the enrolled subjects ranged with a mean of $79 \pm 8$ years (men, $78 \pm 8$ years; women, $79 \pm 8$ years; $P<0.001)$. In men, age, prevalence of antihypertensive medication, and TG showed a gradual increasing trend. In women, age, prevalence of antihypertensive medication, TG and 
prevalence of Ischemic heart disease showed a gradual increasing trend and HDL-C showed a gradual decrease. The prevalence of MetS also showed a gradual increasing according to the UA quartiles in both genders. There were no inter-group differences in prevalence of alcohol consumption, FPG, prevalence of antidiabetic and antilipidemic medication in both genders.

\section{Carotid atherosclerosis of subjects according to quartile of UA}

As shown in Table 2, carotid IMT was significantly increased according to the UA quartiles in both genders without MetS and in women with MetS, but was not necessarily increased in men with MetS. As shown in Figure 1, the prevalence of carotid atherosclerosis was significantly increased with increased UA quartile in both genders without MetS.

\section{Adjusted-odds ratio for carotid atherosclerosis according to quartile of UA and MetS by gender}

In Table 3, to examine possible associations between quartiles of UA and the incidence of carotid atherosclerosis after subdivision of the subjects according to MetS status, multivariate logistic regression analysis was performed adjusted for age, gender, BMI, smoking status, SBP, DBP, antihypertensive medication, LDL-C, HDL-C, TG, antilipidemic medication, FPG, antidiabetic medication, and history of CVD. In men, ORs (95\% CI) were significantly increased in the third $\{1.75$ (1.02$3.02)\}$ and fourth quartiles $\{2.01$ (1.12-3.60)\} of UA compared with that in the first quartile, and in women the OR was significantly increased only in the fourth quartile $\{2.10(1.30-3.39)\}$. Similarly, the ORs were significantly associated with increasing quartiles of UA in both genders without MetS, but not necessarily increased in those with MetS.

\section{Adjusted-odds ratio of subgroups for carotid} atherosclerosis according to quartile of UA by gender Next, to control potential confounding factors by age, BMI, history of CVD, and medication, the data were further stratified by their values (Table 4). In men, the ORs for carotid atherosclerosis were significant in subgroups of age $\geq 75$ years, BMI $\geq 25 \mathrm{~kg} / \mathrm{m}^{2}$, no history of CVD, and absence of medication, and in women the ORs were significant in subgroups of age $<75$ years, BMI $\geq 25 \mathrm{~kg} / \mathrm{m}^{2}$, regardless of history of CVD, presence of medication.

\section{Discussion}

MetS, representing a cluster of visceral obesity, raised $\mathrm{BP}$, dyslipidemia and glucose intolerance induced by insulin resistance, is a common basis for the development of atherosclerosis, especially CVD [3-5]. In our study, MetS as defined by the modified NCEP-ATP III report criteria was present in $27.1 \%$ of men and $34.6 \%$ of women. We found 2 results from this cross-sectional data. First, sex-specific UA quartiles are associated with various risk factors and the prevalence of MetS. Second, UA levels might be associated with carotid atherosclerosis independently of other risk factors in both genders without MetS.

Several previous studies have reported possible associations between hyperuricemia and the prevalence of MetS [22-24]. In a prospective study of 8,429 men and 1,260 women aged 20-82 years, 1,120 men and 44 women developed MetS during a mean follow-up of 5.7 years, and men with UA levels $\geq 6.5 \mathrm{mg} / \mathrm{dL}$ had a 1.60 fold increase in risk of MetS (95\% CI, 1.34-1.91) as compared with those who had levels $<5.5 \mathrm{mg} / \mathrm{dL}$ ( $\mathrm{P}$ for trend $<0.001$ ), and women with UA levels $\geq 4.6 \mathrm{mg} / \mathrm{dL}$ had a 2.29 -fold higher risk of MetS $(P$ for trend $=0.02)$ [22]. These findings suggest that hyperuricemia may be

Table 2 Carotid intima-media thickness of subjects according to quartile of uric acid and metabolic syndrome by gender

\begin{tabular}{|c|c|c|c|c|c|}
\hline \multirow[b]{2}{*}{$\begin{array}{l}\text { Uric acid range } \\
\text { Men }(\mathrm{mg} / \mathrm{dL}) \\
\text { Women }(\mathrm{mg} / \mathrm{dL})\end{array}$} & \multicolumn{4}{|c|}{ Quartile of serum uric acid } & \\
\hline & $\begin{array}{c}\text { UA-1 } \\
0.8-4.3 \\
0.5-3.8\end{array}$ & $\begin{array}{c}\text { UA-2 } \\
4.4-5.5 \\
3.9-4.7\end{array}$ & $\begin{array}{c}\text { UA-3 } \\
5.6-6.8 \\
4.8-6.0\end{array}$ & $\begin{array}{c}\text { UA-4 } \\
6.9-16.1 \\
6.1-15.4\end{array}$ & \\
\hline \multicolumn{6}{|l|}{ All subjects } \\
\hline Men, $N=663$ & $1.02 \pm 0.20 \#$ & $1.06 \pm 0.26$ & $1.03 \pm 0.20 \S$ & $1.13 \pm 0.27$ & $<0.001$ \\
\hline Women, $\mathrm{N}=916$ & $0.97 \pm 0.18 \#$ & $0.98 \pm 0.20 \#$ & $0.99 \pm 0.19 \S$ & $1.06 \pm 0.25$ & $<0.001$ \\
\hline \multicolumn{6}{|c|}{ Subjects without metabolic syndrome ( $<3$ components of metabolic syndrome) } \\
\hline Men, $N=483$ & $1.01 \pm 0.20 \#$ & $1.07 \pm 0.29$ & $1.03 \pm 0.20 \S$ & $1.15 \pm 0.28$ & $<0.001$ \\
\hline Women, $N=599$ & $0.95 \pm 0.18 \S$ & $0.97 \pm 0.19+$ & $0.99 \pm 0.20$ & $1.04 \pm 0.21$ & 0.002 \\
\hline \multicolumn{6}{|c|}{ Subjects with metabolic syndrome ( $\geq 3$ components of metabolic syndrome) } \\
\hline Men, $N=180$ & $1.07 \pm 0.23$ & $1.04 \pm 0.14$ & $1.05 \pm 0.19$ & $1.10 \pm 0.24$ & 0.487 \\
\hline Women, $N=317$ & $1.01 \pm 0.18$ & $0.99 \pm 0.22 \dagger$ & $1.00 \pm 0.19 \dagger$ & $1.10 \pm 0.23$ & 0.004 \\
\hline
\end{tabular}

$+P<0.05 ; \S P<0.005 ; \# P<0.001$ vs. the fourth quartile (UA-4). ${ }^{*} P$-value: ANOVA and Dunnett's test was used for the pos hoc analysis. 


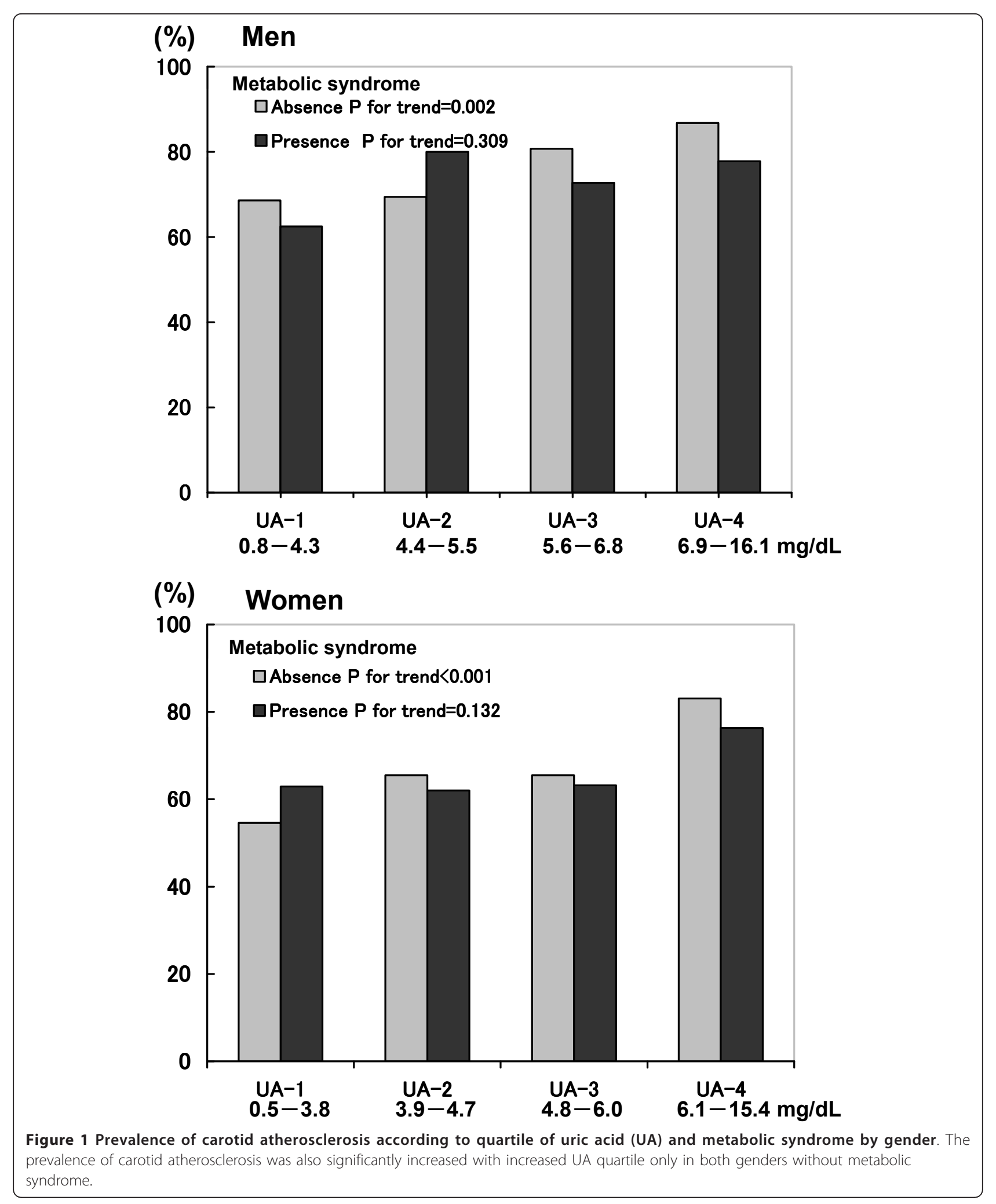


Table 3 Adjusted-odds ratio $(95 \% \mathrm{Cl})$ for carotid atherosclerosis according to quartile of uric acid and metabolic syndrome by gender

\begin{tabular}{|c|c|c|c|c|}
\hline \multirow[b]{2}{*}{$\begin{array}{l}\text { Uric acid range } \\
\text { Men }(\mathrm{mg} / \mathrm{dL}) \\
\text { Women }(\mathrm{mg} / \mathrm{dL})\end{array}$} & \multicolumn{4}{|c|}{ Quartile of serum uric acid } \\
\hline & $\begin{array}{c}\text { UA-1 } \\
0.8-4.3 \\
0.5-3.8\end{array}$ & $\begin{array}{c}\text { UA-2 } \\
4.4-5.5 \\
3.9-4.7\end{array}$ & $\begin{array}{c}\text { UA-3 } \\
5.6-6.8 \\
4.8-6.0\end{array}$ & $\begin{array}{c}\text { UA-4 } \\
6.9-16.1 \\
6.1-15.4\end{array}$ \\
\hline \multicolumn{5}{|l|}{ All subjects } \\
\hline Men, $N=663$ & 1 (reference) & $1.06(0.63-1.76)$ & $1.75(1.02-3.02)+$ & $2.01(1.12-3.60)+$ \\
\hline Women, $\mathrm{N}=916$ & 1 (reference) & $1.44(0.94-2.21)$ & $1.29(0.84-1.98)$ & $2.10(1.30-3.39) \S$ \\
\hline \multicolumn{5}{|c|}{ Subjects without metabolic syndrome ( $<3$ components of metabolic syndrome) } \\
\hline Men, $N=483$ & 1 (reference) & $0.92(0.51-1.67)$ & $2.00(1.03-3.87)+$ & $2.54(1.21-5.34) \neq$ \\
\hline Women, $\mathrm{N}=599$ & 1 (reference) & $1.78(1.06-3.00) \dagger$ & $1.41(0.83-2.40)$ & $2.54(1.35-4.78) \S$ \\
\hline \multicolumn{5}{|c|}{ Subjects with metabolic syndrome ( $\geq 3$ components of metabolic syndrome) } \\
\hline Men, $N=180$ & 1 (reference) & $2.14(0.67-6.81)$ & $1.55(0.50-4.83)$ & $2.26(0.72-7.10)$ \\
\hline Women, $N=317$ & 1 (reference) & $0.81(0.36-1.79)$ & $1.12(0.51-2.49)$ & $1.43(0.62-3.27)$ \\
\hline
\end{tabular}

$\mathrm{Cl}$, confidential interval. Adjusted for age, body mass index, smoking status, systolic blood pressure, diastolic blood pressure, antihypertensive medication, LDLcholesterol, HDL-cholesterol, triglycerides, antilipidemic medication, fasting plasma glucose, antidiabetic medication, and history of cardiovascular disease. $\dagger P<$ $0.05 ; \neq P<0.01 ; \S P<0.005$ vs. the first quartile (UA-1).

another component of MetS [24]. We thought that sexspecific analyses were also required because at all ages, the UA level is higher in men than in women $[22,23]$. We cannot explain the underlying mechanism that accounts for the gender difference from this study. A partial explanation for this result could be alcohol consumption, which is more likely to be higher in men, the use of antihypertensive medications such as diuretics, which are known to increase UA levels [25], and the influence of sex hormones [26]. Furthermore, UA tends to positively associate with FPG in subjects without diabetes and negatively associate with FPG in subjects with diabetes [27]. In our study, the analysis was performed after adjusting for FPG, medication, and alcohol

Table 4 Adjusted-odds ratio $(95 \% \mathrm{Cl})$ of subgroups for carotid atherosclerosis according to quartile of uric acid by gender

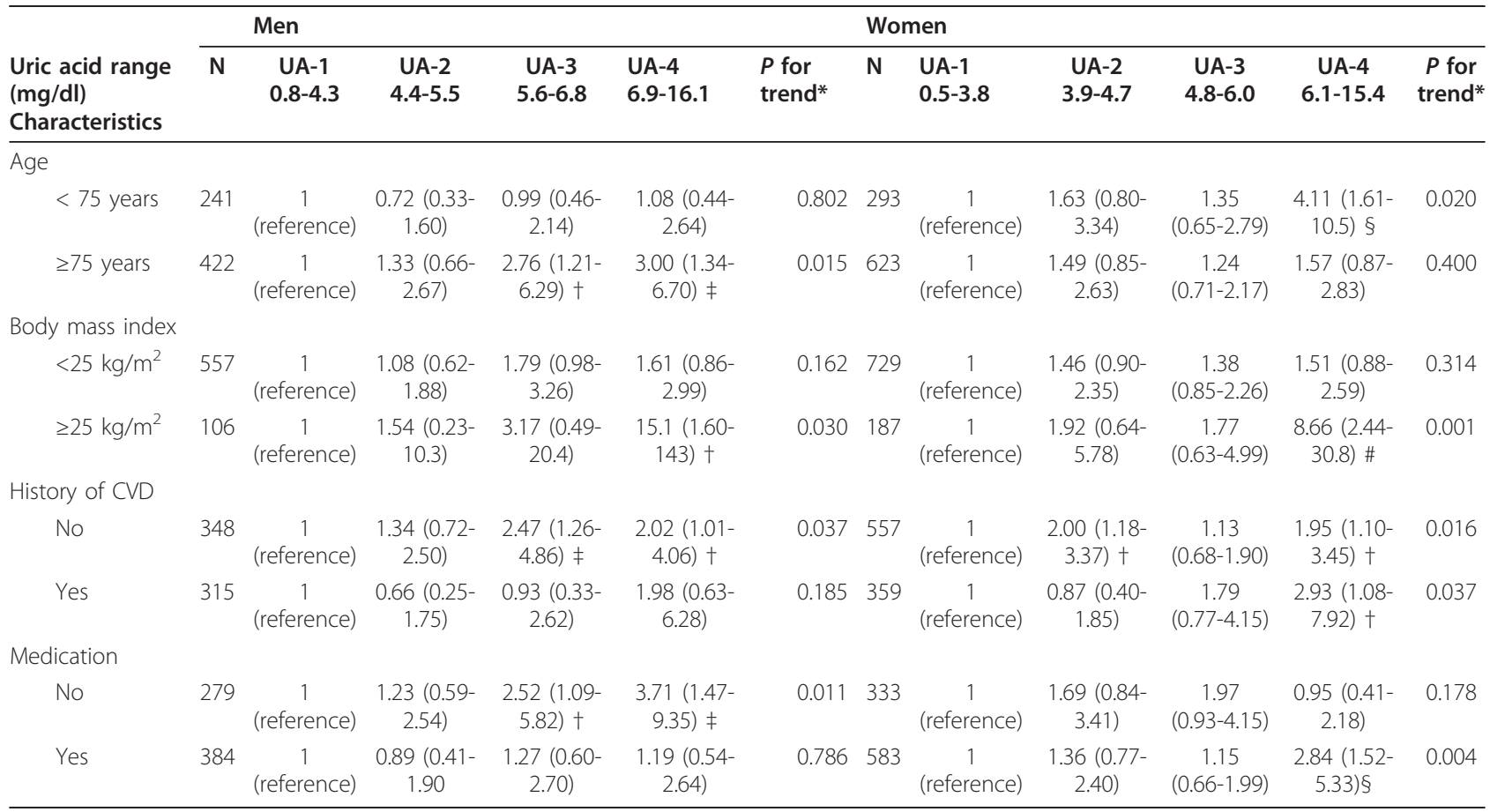

CVD, cardiovascular disease. Medications include antihypertensive, antilipidemic, and antidiabetic medications. Adjusted for age, body mass index, smoking status, systolic blood pressure, diastolic blood pressure, antihypertensive medication, LDL-cholesterol, HDL-cholesterol, triglycerides, antilipidemic medication, fasting plasma glucose, antidiabetic medication, and history of cardiovascular disease. $+P<0.05 ; \neq P<0.01 ; \S P<0.005 ; \# P<0.001$ vs. the first quartile (UA-1). 
consumption (data not shown), but the results were similar. Effects of alcohol consumption or sex hormone require further investigation in the future.

Hyperuricemia is well recognized as a risk factor for atherosclerotic diseases such as CVD $[12,13]$ and carotid atherosclerosis [28-34]. However, whether UA is an independent risk factor for cardiovascular mortality is still a controversy, as previous studies suggest that UA is associated with other cardiovascular risk factors [8-11] despite the strengths of the associations. In crosssectional screening data from 8,144 individuals, the prevalence of carotid plaque was significantly higher with increasing quartiles of UA level, in men without MetS but not in men with MetS or in women with or without MetS [32]. On the other hand, in a prospective study of 4,966 men ( $79 \%$ white) and 6,522 women ( $74 \%$ white) who were aged 45 to 64 years at baseline, after adjustment for known risk factors that correlate with UA, the association of UA with B-mode ultrasound carotid IMT became non significant in white women and much weaker and not statistically significant in black women and white men [33]. These conflicting findings are partly related to methodological differences and to participant characteristics. In addition, as UA revels relate with increasing numbers of or special metabolic risk factors, the effect of UA on carotid atherosclerosis might become negligible.

The mechanisms by which UA reflects the risk for carotid atherosclerosis are not completely understood even though previous studies have been done in this area, and it is unclear whether high UA levels promote or protect against the development of CVD, or simply act as a passive marker of increased risk. UA regulates critical proinflammatory pathways in vascular smooth muscle cells. Hyperuricemia might be partially responsible for the proinflammatory endocrine imbalance in the adipose tissue and vascular smooth muscle cells $[35,36]$ which is an underlying mechanism of the low-grade inflammation and insulin resistance in subjects with the MetS, and causes dysfunction of endothelial cells. In addition, experimental evidence suggests that adverse effects of UA on the vasculature have been linked to increased chemokine and cytokine expressions, induction of the renin-angiotensin system, and to increased vascular C-reactive protein (CRP) expression [37]. UA also promotes endothelial dysfunction through inactivation of $\mathrm{NO}$ and suppression of the proliferation of endothelial cells [38]. Thus, arteriosclerosis induced by hyperuricemia may be a novel mechanism for the development of MetS and carotid atherosclerosis. However, Nieto et al. demonstrated that the higher UA levels seemed associated with elevated total serum antioxidant capacity among individuals with carotid atherosclerosis and be a powerful free radical scavenger in humans
[39]. These antioxidant properties of UA could be expected to offer a number of benefits within the cardiovascular system.

We need to be aware of the limitations in interpreting the present results. First, based on its cross-sectional study design, the present result is inherently limited in its ability to elucidate causal relationships between risk factors and carotid atherosclerosis. Second, since all participants were patients, we could not eliminate the possible effects of underlying diseases (e.g., hypertension and diabetes), alcohol consumption, medication (e.g., diuretics, antihyperuricemic and antilipidemic medications) and FPG on the results. Thus, the analysis was performed after adjusting for confounding factors including FPG and medication (e.g., antihypertensive, antilipidemic, and antidiabetic medication). Third, we used BMI $\geq 25 \mathrm{~kg} / \mathrm{m}^{2}$ to classify individuals with visceral obesity because waist circumference measurements were not available, which might have caused an under or over estimation of the effect of visceral obesity on MetS. In fact, the prevalence of MetS in women was higher than those in men and general reports on Japanese [40]. Moreover, secondary prevention interventions after obesity, raised BP, dyslipidemia and diabetes may be successful in reducing risk factors, thus attenuating the observed association of risk factors with diseases. These points need to be addressed again in prospective population-based studies.

In sum, we reported a significant association between the clustering of cardiovascular risk factors known as MetS and UA, and carotid IMT in subjects with risk factors for atherosclerosis. In both genders that did not have MetS, UA was found to be an independent risk factor for the incidence of carotid atherosclerosis. Serum UA confers an increased risk of cardiovascular morbidity, and its identification may thus be important for risk assessment and treatment of patients.

\section{Acknowledgements}

This work was supported in part by a grant-in-aid for Scientific Research from the Foundation for Development of Community (2011).

\section{Author details}

'Department of Community Medicine, Ehime University Graduate School of Medicine; Ehime 791-0295, Japan. ${ }^{2}$ Gastroenterology and Metabology, Ehime University Graduate School of Medicine; Ehime 791-0295, Japan.

${ }^{3}$ Department of Internal Medicine, Seiyo Municipal Nomura Hospital, Ehime 797-1212, Japan.

\section{Authors' contributions}

ST, RK, and MO participated in the design of the study, performed the statistical analysis and drafted the manuscript. TK and MA contributed to the acquisition of data and its interpretation. MO conceived of the study, participated in its design, coordination and helped to draft the manuscript. All authors read and approved the manuscript.

\section{Competing interests}

The authors declare that they have no competing interests. 
Received: 18 December 2011 Accepted: 10 January 2012

Published: 10 January 2012

\section{References}

1. National Cholesterol Education Program: Executive Summary of The Third Report of The National Cholesterol Education Program (NCEP) Expert Panel on Detection, Evaluation, And Treatment of High Blood Cholesterol In Adults (Adult Treatment Panel III). JAMA 2001. 285:2486-2497.

2. Grundy SM, Cleeman II, Daniels SR, Donato KA, Eckel RH, Franklin BA, Gordon DJ, Krauss RM, Savage PJ, Smith SC Jr, Spertus JA, Costa F: American Heart Association; National Heart and Blood Institute: Diagnosis and management of the metabolic syndrome: an American Heart Association/National Heart, Lung, and Blood Institute Scientific Statement. Circulation 2005, 112:2735-2752.

3. Wilson PW, D'Agostino RB, Parise H, Sullivan L, Meigs JB: Metabolic syndrome as a precursor of cardiovascular disease and type 2 diabetes mellitus. Circulation 2005, 112:3066-3072.

4. McNeill AM, Katz R, Girman CJ, Rosamond WD, Wagenknecht LE, Barzilay JI, Tracy RP, Savage PJ, Jackson SA: Metabolic syndrome and cardiovascular disease in older people: The cardiovascular health study. J Am Geriatr Soc 2006, 54:1317-1324.

5. Lorenzo C, Williams K, Hunt KJ, Haffner SM: The National Cholesterol Education Program - Adult Treatment Panel III, International Diabetes Federation, and World Health Organization definitions of the metabolic syndrome as predictors of incident cardiovascular disease and diabetes. Diabetes Care 2007, 30:8-13.

6. Shiwaku K, Nogi A, Kitajima K, Anuurad E, Enkhmaa B, Yamasaki M, Kim JM, Kim IS, Lee SK, Oyunsuren T, Yamane Y: Prevalence of the metabolic syndrome using the modified ATP III definitions for workers in Japan Korea and Mongolia. J Occup Health 2005, 47:126-135.

7. So A, Thorens B: Uric acid transport and disease. Journal of Clinical Investigation 2010, 120:1791-1799.

8. Taniguchi Y, Hayashi T, Tsumura K, Endo G, Fujii S, Okada K: Serum uric acid and the risk for hypertension and Type 2 diabetes in Japanese men: The Osaka Health Survey. J Hypertens 2001, 19:1209-1215.

9. Milionis HJ, Kakafika Al, Tsouli SG, Athyros VG, Bairaktari ET, Seferiadis KI, Elisaf MS: Effects of statin treatment on uric acid homeostasis in patients with primary hyperlipidemia. Am Heart J 2004, 148:635-640.

10. Lee J, Sparrow D, Vokonas PS, Landsberg L, Weiss ST: Uric acid and coronary heart disease risk: evidence for a role of uric acid in the obesity-insulin resistance syndrome. The Normative Aging Study. Am J Epidemiol 1995, 142:288-294.

11. Cappuccio FP, Strazzullo P, Farinaro E, Trevisan M: Uric acid metabolism and tubular sodium handling. Results from a population-based study. JAMA 1993, 270:354-359.

12. Fang J, Alderman MH: Serum uric acid and cardiovascular mortality the NHANES I epidemiologic follow-up study, 1971-1992. National Health and Nutrition Examination Survey. JAMA 2000, 283:2404-2410.

13. Gagliardi AC, Miname MH, Santos RD: Uric acid: A marker of increased cardiovascular risk. Atherosclerosis 2009, 202:11-17.

14. Sakata K, Hashimoto T, Ueshima H, Okayama A, NIPPON DATA 80 Research Group: Absence of an association between serum uric acid and mortality from cardiovascular disease: NIPPON DATA 80, 1980-1994. National Integrated Projects for Prospective Observation of Non-communicable Diseases and its Trend in the Aged. Eur J Epidemiol 2001, 17:461-468

15. Kawamoto R, Tomita H, Oka Y, Ohtsuka N: Relationship between serum uric acid concentration, metabolic syndrome and carotid atherosclerosis. Intern Med 2006, 45:605-614.

16. Friedewald WT, Levy RI: Fredrickson DS: Estimation of the concentration of low-density lipoprotein cholesterol in plasma, without use of the preparative ultracentrifuge. Clin Chem 1972, 18:499-502.

17. Salonen JT, Salonen R: Ultrasonographically assessed carotid morphology and the risk of coronary heart disease. Arter Throm 1991, 11:1245-1249.

18. Sidhu PS, Desai SR: A simple and reproducible method for assessing intima-media thickness of the common carotid artery. Br J Radiol 1997, 70:85-89.

19. Prati P, Vanuzzo D, Casaroli M, Di Chiara A, De Biasi F, Feruglio GA, Touboul PJ: Prevalence and determinants of carotid atherosclerosis in a general population. Stroke 2002, 23:1705-1711.
20. The examination Committee of Criteria for "Obesity Disease" in Japan: Japan Society for Study of Obesity. New criteria for 'obesity disease' in Japan. Circ J 2002, 66:987-992.

21. Ota T, Takamura T, Hirai N, Kobayashi K: Preobesity in World Health Organization classification involves the metabolic syndrome in Japanese. Diabetes Care 2002, 25:1252-1253

22. Sui X, Church TS, Meriwether RA, Lobelo F, Blair SN: Uric acid and the development of metabolic syndrome in women and men. Metabolism 2008, 57:845-852.

23. Chiou WK, Wang MH, Huang DH, Chiu HT, Lee YJ, Lin JD: The relationship between serum uric acid level and metabolic syndrome: differences by sex and age in Taiwanese. J Epidemiol 2010, 20:219-224.

24. Tsouli SG, Liberopoulos EN, Mikhailidis DP, Athyros VG, Elisaf MS: Elevated serum uric acid levels in metabolic syndrome: an active component or an innocent bystander? Metabolism 2006, 55:1293-1301.

25. Savage PJ, Pressel SL, Curb JD, Schron EB, Applegate WB, Black HR, Cohen J, Davis BR, Frost P, Smith W, Gonzalez N, Guthrie GP, Oberman A, Rutan G, Probstfield JL, Stamler J: Influence of long-term, low-dose, diuretic-based, antihypertensive therapy on glucose, lipid, uric acid, and potassium levels in older men and women with isolated systolic hypertension: The Systolic Hypertension in the Elderly Program. SHEP Cooperative Research Group. Arch Intern Med 1998, 158:741-751.

26. Gordon T, Kannel WB: Drinking and its relation to smoking, BP, blood lipids, and uric acid. The Framingham study. Arch Intern Med 1983, 143:1366-1374.

27. Nan H, Dong Y, Gao W, Tuomilehto J, Qiao Q: Diabetes associated with a low serum uric acid level in a general Chinese population. Diabetes Res Clin Pract 2007, 76:68-74.

28. Neogi T, Ellison RC, Hunt S, Terkeltaub R, Felson DT, Zhang Y: Serum uric acid is associated with carotid plaques: the National Heart, Lung, and Blood Institute Family Heart Study. J Rheumatol 2009, 36:378-384.

29. Li Q, Yang Z, Lu B, Wen J, Ye Z, Chen L, He M, Tao X, Zhang W, Huang Y, Zhang Z, Qu S, Hu R: Serum uric acid level and its association with metabolic syndrome and carotid atherosclerosis in patients with type 2 diabetes. Cardiovascular Diabetology 2011, 10:72, Aug 2011

30. Tavil Y, Kaya MG, Oktar SO, Sen N, Okyay K, Yazici HU, Cengel A: Uric acid level and its association with carotid intima-media thickness in patients with hypertension. Atherosclerosis 2008, 197:159-163.

31. Montalcini T, Gorgone G, Gazzaruso C, Sesti G, Perticone F, Pujia A: Relation between serum uric acid and carotid intima-media thickness in healthy postmenopausal women. Intern Emerg Med 2007, 2:19-23.

32. Ishizaka N, Ishizaka Y, Toda E, Nagai R, Yamakado M: Association between serum uric acid, metabolic syndrome, and carotid atherosclerosis in Japanese individuals. Arterioscler Thromb Vasc Biol 2005, 25:1038-1044.

33. Iribarren C, Folsom AR, Eckfeldt JH, McGovern PG, Nieto FJ: Correlates of uric acid and its association with asymptomatic carotid atherosclerosis: the ARIC Study. Atherosclerosis Risk in Communities. Ann Epidemiol 1996, 6:331-340

34. Pan WH, Bai CH, Chen JR, Chiu HC: Associations between carotid atherosclerosis and high factor VIII -activity, dyslipidemia, and hypertension. Stroke 1997, 28:88-94

35. Kanellis J, Watanabe S, Li JH, Kang DH, Li P, Nakagawa T, Wamsley A, Sheikh-Hamad D, Lan HY, Feng L, Johnson RJ: Uric Acid Stimulates Monocyte Chemoattractant Protein-1 Production in Vascular Smooth Muscle Cells Via Mitogen-Activated Protein Kinase and Cyclooxygenase2. Hypertension 2003, 41:1287-1293.

36. Baldwin WMS, Marek G, Wymer D, Pannu V, Baylis C, Johnson RJ, Sautin YY: Hyperuricemia as a Mediator of the Proinflammatory Endocrine Imbalance in the Adipose Tissue in a Murine Model of the Metabolic Syndrome. Diabetes 2011, 60:1258-1269

37. Kanellis J, Kang DH: Uric acid as a mediator of endothelial dysfunction, inflammation, and vascular disease. Semin Nephrol 2005, 25:39-42.

38. Sánchez-Lozada LG, Nakagawa T, Kang DH, Feig DI, Franco M, Johnson RJ, Herrera-Acosta J: Hormonal and cytokine effects of uric acid. Curr Opin Nephrol Hypertens 2006, 15:30-33.

39. Nieto FJ, lribarren C, Gross MD, Comstock GW, Cutler RG: Uric acid and serum antioxidant capacity: a reaction to atherosclerosis? Atherosclerosis 2000, 148:131-139

40. Oda E, Kawai R: Reproducibility of high-sensitivity C-reactive protein as an inflammatory component of metabolic syndrome in Japanese. Circ $J$ 2010, 74:1488-1493. 
doi:10.1186/1475-2840-11-2

Cite this article as: Takayama et al:: Uric acid is an independent risk

factor for carotid atherosclerosis in a Japanese elderly population

without metabolic syndrome. Cardiovascular Diabetology 2012 11:2.

Submit your next manuscript to BioMed Central and take full advantage of:

- Convenient online submission

- Thorough peer review

- No space constraints or color figure charges

- Immediate publication on acceptance

- Inclusion in PubMed, CAS, Scopus and Google Scholar

- Research which is freely available for redistribution

Submit your manuscript at 